\title{
PEdicádAGóGiCA No.11
}

\section{Contenido}

Editorial

Investigación cientifica y desarrollo

Una propuesta para trabajar la motricidad

en educación infantil a través del aprendizaje inducido

Seminario de Educación Física en Educación Infantil (E.U. Magisterio de Segovia, España).

Victor M. López Pastor (coord.), María Ascensión Antón Miñambres, José Manuel García de la Puente,

Roberto Hidalgo Sandin, Irene Llorente Lumbreras, Helena Pescador López, Laura Vázquez Santamaría

Una estrategia tecnológica para el aprendizaje del reglamento de baloncesto mediada por las capacidades cognitivas: memorizar, relacionar y discriminar.

Sonia Rocío Corredor Castro

Caracterización de las escuelas de formación deportiva inscritas en el

Instituto Distrital para la Recreación y el Deporte de Bogotá en 2005.

Jairo Rosas Tibabuzo, Óscar Horacio Bernal Triviño, Andrés Castellanos

El pensamiento del profesor de Educación Física:

un acercamiento a las prácticas educativas institucionales.

Martha Ibette Correa Olarte, Nelly Teresa Martínez

Ciclismo saludable bajo techo

Édgar A. Rodríguez Manchola, Diego Ermith Corredor, Angélica Avendaño Valencia

Reflexiones originales

Aspectos psicosociales y éticos del dopaje.

Rubén Alberto Cadavid Villa

Poder, tiempo libre y recreación.

Juan Manuel Carreño Cardozo

Concepciones de los profesores de Educación Física

sobre el deporte: de la hegemonía a la utopía.

Alberto Calderón García

Edificación de la competencia motriz

y conquista de las realizaciones personales.

Luis Felipe Brito Soto

Los modelos de entrenadores y educadores en el escenario del deporte escolar.

Antonio Fraile Aranda

Entrenamiento propioceptivo para futbolistas, una propuesta desde la fisioterapia.

Manuel Alberto Riveros Medina

La psicomotricidad como alternativa de reivindicación

de la importancia del cuerpo y el movimiento para el desarrollo humano.

Álvaro José Gracia Díaz

\section{Ponencias}

Las prácticas corporales y su relación con la pedagogía

en la escuela colombiana en 1935

Astrid Bibiana Rodríguez Cortés

\section{Traducciones}

Evaluación del salto de jugadores elite de voleibol mediante dos métodos: ecuaciones de potencia de salto y plataforma de fuerza.

C. Hertogh, O. Hue

Traducción de Daniel Ignacio Oliveros Wilches 
In cordial saludo a todos los lectores de nuestra revista Lúdica Pedagógica.

En este número presentamos artículos sobre los tres campos de trabajo académico que la Facultad de Educación Física ha adoptado en su estructura de indagación y formación: educación física, recreación y deporte, en los cuales se refleja el conjunto de preocupaciones por las que atraviesa el pensamiento teórico de nuestra Facultad.

Estos espacios de reflexión, investigación y práctica han sido tradicionalmente concebidos bajo la denominación amplia de la Educación Física. Sin embargo, en la Universidad Pedagógica Nacional hemos considerado que es necesario asumir la tarea de estudiarlos como tres entidades con distinciones o características diferentes, no obstante sus zonas comunes.

Nuestra portada refleja esta manera de visualizar los campos. Proponemos que la educación física debe identificar su posición y su función frente a sí misma y en relación con el deporte, y a la vez, éste debe hacerlo con relación a ella, pero ambos deben asumir la reflexión sobre su zona común o de intersección. Es decir, analizar y tomar posición sobre el deporte escolar, la educación deportiva e incluso sobre las escuelas de formación deportiva. De la misma manera se debe proceder entre la recreación y la educación física. ¿Qué planteamientos debe hacer la educación física en la perspectiva de educar para la recreación y en la recreación? ¿Cuál es el papel de la escuela, no sólo de la Educación Física como asignatura obligatoria, frente a la educación para la recreación? En este sentido hay muchos interrogantes que pueden asumirse desde la zona de intersección de estos dos campos. Y, por supuesto, igual tarea se deriva para la relación entre deporte y recreación en relación con su zona de intersección disciplinar y práctica, en la cual hay mucho que estudiar sobre el papel del deporte recreativo y de la recreación deportiva.

Las perspectivas de investigación de estos campos y de sus zonas compartidas no podrán asumirse desde análisis netamente cuantitativos. Claro que las estadísticas ayudan; por ejemplo, cuántas personas están en cada uno de estos campos es una perspectiva interesante, o qué cantidad de presupuesto se dedica a cada campo. Pero creemos que es necesario también asumir la perspectiva de investigación desde el ámbito cualitativo; por ejemplo, desde la pedagogía social o cultural, o desde la interculturalidad.

Asimismo, aprovecho este espacio de la revista para despedirme de la posición de Decano de la Facultad de Educación Física de la Universidad, luego de un periodo en el cual se aprueban tres pregrados y se logra el registro calificado de tres especializaciones; la investigación avanza, se ha empezado a difundir lo que hemos encontrado en el camino en cursos de formación de maestros y encuentros de investigadores, y la Facultad tendrá nueva sede en Valmaría, al norte de la ciudad, donde pronto se empezará la labor docente.

Finalmente, damos la bienvenida al nuevo Decano, el profesor José Alfonso Martín, quien asume la dirección de la Facultad por los próximos cuatro años, con apoyo democrático y con perspectivas de excelencia en su labor. Nuestros mejores deseos en su gestión. 